\title{
Research Paper: Affective and Emotional Temperament in Trauma-exposed Women With and Without Post-traumatic Stress Disorder Following Intimate Partner Violence
}

\author{
Masumeh Shafiei $^{1}$ (D), Somayeh Daneshvar ${ }^{2^{*}}$ (D), Sajjad Basharpour ${ }^{3}$ (D), Mina Taherifard ${ }^{3}$ (D) \\ 1. Department of Psychology, Faculty of Literature and Human Sciences, Lorestan University, Khoramabad, Iran. \\ 2. Department of Clinical Psychology, Faculty of Educational Sciences and Psychology, Shiraz University, Shiraz, Iran. \\ 3. Department of Psychology, Faculty of Educational Sciences and Psychology, University of Mohaghegh Ardabili, Ardabil, Iran.
}

\begin{tabular}{|c|c|}
\hline $\begin{array}{l}\text { Use your device to scan } \\
\text { and read the article online }\end{array}$ & dreation Shafiei, M., Daneshvar, S., Basharpoor, S., \& Taherifard, M. (2021). Affective and Emotional Temperament in \\
\hline 口fitg & Trauma-exposed Women With and Without Post-traumatic Stress Disorder Following Intimate Partner Violence. Journal of \\
\hline & Practice in Clinical Psychology, 9(4), 283-292. https://doi.org/10.32598/jpcp.9.4.769.1 \\
\hline anis & doli'https://doi.org/10.32598/jpcp.9.4.769.1 \\
\hline
\end{tabular}

\section{(c) (1) (\$)}

Article info:

Received: 14 Apr 2021

Accepted: 21 Aug 2021

Available Online: 01 Oct 2021

Keywords:

Affect, Emotion, Temperament, Trauma, Posttraumatic stress disorder, Violence

\section{ABSTRACT}

Objective: The present study was done to compare emotional and affective temperament in trauma-exposed women with and without Post-Traumatic Stress Disorder (PTSD) following intimate partner violence.

Methods: A total of 195 trauma-exposed women with and without PTSD participated in this study, and completed the Affective and Emotional Composite Temperament Scale (AFECTS). Collected data were analyzed by Multivariate Analysis of Variance (MANOVA).

Results: The mean scores of the group with PTSD were significantly higher compared to the group without PTSD in the overall scores of affective temperament, including cyclothymic, depressive, anxious, apathetic, Volatile, Dysphoric, obsessive, euthymic, disinhibited, euphoric, and also the emotional temperament, including anger and sensitivity.

Conclusion: Findings suggest that emotional and affective temperament can increase the risk of developing PTSD following exposure to intimate partner violence.

\section{* Corresponding Author:}

Somayeh Daneshvar, PhD.

Address: Department of Clinical Psychology, Faculty of Educational Sciences and Psychology, Shiraz University, Shiraz, Iran.

Tel: +98 (930) 0629252

E-mail: somayeh.daneshvar@shirazu.ac.ir 


\section{Highlights}

- Female victims of intimate partner violence suffering from PTSD show higher levels of affective temperament compared to the female victims of intimate partner violence without PTSD;

- Female victims of intimate partner violence suffering from PTSD show higher levels of emotional temperament compared to the female victims of intimate partner violence without PTSD;

- Emotional and affective temperament can increase the risk of developing PTSD following exposure to intimate partner violence.

\section{Plain Language Summary}

In this study, we investigated the temperamental features- which is one of the factors that affect how people react to trauma- in female victims of Intimate Partner Violence (IPV) with and without Post-Traumatic Stress Disorder (PTSD). Given the high prevalence of IPV in Iran and its significant role in developing psychiatric disorders in women, which is observed as psychological abuse, physical violence, sexual coercion, controlling behaviors, and stalking, investigating on the psychological aspects of this issue is important. In this regard, we assessed the affective and emotional temperament on 195 trauma-exposed women with and without PTSD following IPV using an integrative temperament model named the Affective and Emotional Composite Temperament Scale (AFECTS). Our findings showed a significantly higher level of affective temperament including cyclothymic, depressive, anxious, apathetic, Volatile, Dysphoric, obsessive, euthymic, disinhibited, and euphoric in subjects with PTSD, relative to the non-PTSD subjects. The emotional temperament including anger and sensitivity was also higher in subjects with PTSD, when compared to the non-PTSD ones. Our findings represent the significant role of affective and emotional temperament in developing PTSD following exposure to intimate partner violence, and highlight the importance of considering affective and emotional temperament for psychotherapists while determining treatment plan for patients with PTSD.

\section{Introduction}

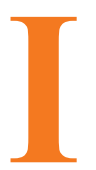

ntimate Partner Violence (IPV) plays a significant role in developing psychiatric disorders in women worldwide, which is observed as psychological abuse, physical violence, sexual coercion, controlling behaviors, and stalking (Orang, 2018). Based on Walker (199), IPV is "a pattern of abusive behaviors, including several sexual, physical, and psychological maltreatment used by an individual in an intimate relationship against another for gaining power unfairly or maintaining the person's misuse of control, power, and authority". The overall incidence of domestic violence against married women has been estimated at about $66.3 \%$ in 28 provincial capitals of Iran, in which about $30 \%$ of participants showed serious physical violence during the marriage (Vameghi, Khodaie Ardakani, \& Sajjadi, 2013). Moghaddam Hosseini, Asadi, Akaberi, and Hashemian (2013) assessed 251 married Iranian women and indicated that the prevalence of overall violence was about $78 \%$, and $38 \%$ of respondents reported minor violence while $40 \%$ of respondents reported both acute and minor types of violence, and $1 \%$ reported only severe forms of violence. Post-Traumatic Stress Disorder (PTSD) is a detrimental psychiatric outcome of IPV (Orang, 2018). The WHO estimates that one in three women throughout the world will experience IPV in their lifetime (World Health Organization, 2017). All types of IPV, including emotional, physical, and sexual abuse, risk of committing murder, and threats of violence, can predict the severity of PTSD symptoms (Wineman, Woods, \& Zupanic, 2004). The outstanding symptoms of PTSD are avoidance, intrusions, negative alternations in mood and cognition, and changes in reactivity and arousal (American Psychiatric Association, 2019). These symptoms lead to impairment in the job, social, and academic functioning of patients with PTSD (Chossegros et al., 2011). Golding (1999) conducted a meta-analysis and declared that the mean prevalence of PTSD in traumatized women following IPV was $63.8 \%$. This researcher reported a marked dose-response association between experiencing IPV and PTSD symptom severity.

Temperament is one of the factors that affect how people react to trauma. Based on the biological theory of personality discussed by Gray (1991), temperament has two independent dimensions of activation (anger and drives) and inhibition (fear and alarm), in which different affective temperaments can be developed via combining them. 
Lara, Bisol, Brunstein, Reppold, de Carvalho and Ottoni (2012) developed the Affective and Emotional Composite Temperament (AFECT) model as an integrative temperament model that includes specific emotional features (Cloninger, Svrakic, \& Przybeck, 1993) and universal affective traits (Akiskal et al., 2005). Lara et al. (2012) described the emotional trait system of this model that includes inhibition, activation, coping, sensitivity, and control. They discussed activation via volition (motivation, positive affect, and energy), desire (impulses and indulgence), and anger (aggressive behavior and emotional intensity). They defined inhibition through fear (shyness, worry, and fearfulness) and caution (carefulness, prudence, and risk avoidance). They also considered emotional sensitivity as being linked to vulnerability to interpersonal friction (e.g. criticism and rejection) and events (pressure, frustration, and traumas). According to Lara et al. (2012), coping factor determines the way that people confront and solves difficult situations that would consequently results in personal growth; control can detect the environment (attention) and develop adaptation (discipline, sense of duty, and planning), i.e. executive functions. Besides, according to Lara et al. (2012), the affective temperament is created by the interaction of emotional traits, which is categorized into 12 types, including internalized types (anxious, depressive, and apathetic), unstable types (cyclothymic, volatile, and dysphoric), stable types (hyperthymic, obsessive, and euthymic), and externalized types (euphoric, irritable, and disinhibited). They considered the AFECT model as being influenced by various factors, like volition, behavior, cognition, attention, perception, mood, and affection. According to Clark (2005) and Patrick and Bernat (2006), affective and emotional temperaments are the basic elements in realizing health- and psychopathology-related issues; these constructs can be also helpful in evaluating, diagnosing, and treating disorders (Carta, Balestrieri, Murru, \& Hardoy, 2009). Karvat Gracia, Lara, Ottoni, and de Araújoc (2019) studied the relationship between temperament and psychological symptoms through the AFECT model. Their results suggested that temperament assessment by the AFECT model can evaluate the risk of developing psychological symptoms.

Temperament is a crucial psychological element in determining individuals' vulnerability against traumatic events; it is also linked to emotional reactions, specifically in interaction with the intensity of injuries and severe PTSD symptoms (Zawadzki \& Agnieszka, 2012). Accordingly, some temperamental traits may lead to an increase in PTSD symptoms in traumatized people, while these symptoms may diminish through gaining social supports (Rzeszutek, Oniszczenko, Schier,
Biernat-Kałuża, \& Gasik, 2015). Besides, PTSD and its consequences are strongly predicted by individuals' temperamental traits and the severity of traumatic events (Jan \& Bogdan, 2004). Cyniak- Cieciura and Zawadzki (2019) studied the relationship between temperament traits and PTSD symptoms in a meta-analysis and reported that all temperament traits, including sensory sensitivity, briskness, perseveration, emotional reactivity, endurance, and activity -defined based on the Regulative Theory of Temperament- were significantly related to PTSD symptoms.

Marwaha, Parsons, and Broome (2013) reported the high levels of temperamental fluctuation in PTSD patients, and also the crucial role of this factor in rising the probability of developing PTSD, as well. Temperamental differences among individuals can play significant roles in the degree to which females experience IPV indicate trauma-related symptoms, including PTSD symptoms (Widiger \& Smith, 2008). This influence is both directly and indirectly. A meta-analysis study showed that given the direct influence of temperament traits, negative emotionality is significantly correlated with more trauma symptoms, while constraint and positive emotionality are significantly linked to fewer trauma symptoms (Kotov, Gamez, Schmidt, \& Watson 2010). Moreover, considering the indirect influence, Miller (2003) declared negative emotionality as a general risk factor to develop trauma symptoms, because it is robustly related to increased reactivity to stress. This researcher argued that trauma-exposed individuals with high levels of negative emotionality indicate a worsened posttraumatic response when compared to those with low levels of negative emotionality. This pattern has been shown in multiple studies on clinical participants (Forbes, Elhai, Miller, \& Creamer, 2010; Miller, Greif, \& Smith, 2003), including female survivors of sexual violence (Miller \& Resick, 2007). Miller (2003) described high constraint as a particular vulnerability for internalizing trauma-related symptoms, which is the consequence of the significant correlation between high constraint and the propensity to ruminate the traumatic event. He considered high positive emotionality as a protective factor against developing trauma-related symptoms; the propensity to experience positive emotions can help trauma-exposed individuals to hold up their mental health through experiencing positive emotions in other aspects of life (sympathetic and warm relationships with individuals other than their violent partners). Furthermore, Brown, Bruce, Buchholz, Artime, Hu, and Sheline (2014) suggested the significant role of negative affective temperament in predicting PTSD symptoms, specifically re-experiencing symptoms. Panic symptoms have also been associated 
with suicidal thoughts, behavior, and depression, which are also more robust among those with PTSD (Albanese, Norr, Capron, Zvolensky, \& Schmidt, 2015). Besides, Clapp, Patton, and Beck (2015) considered inhibition as a probable mechanism in emotional dysregulation in PTSD patients. Consistently, Duffy, Jadidian, Douglass, and Allan (2015) revealed the significant association of PTSD symptoms with neuroticism, consciousness, and volition as well.

Ultimately, considering the above-mentioned research findings, it can be claimed that PTSD symptoms are not only associated with emotion regulation but are also linked to affective and emotional temperament. Accordingly, we can highlight the psychological factors that may mediate the relation between trauma exposure and developing PTSD following trauma exposure. According to the investigations, one of these psychological factors is emotional and affective temperament. Different dimensions of this construct have been investigated in several studies; nevertheless, to the best of our knowledge, there is no research on multiple dimensions of emotional and affective temperament in traumatized women with and without PTSD following IPV. Therefore, this study investigated the affective and emotional temperament in traumatized women with and without PTSD following IPV.

\section{Materials and Methods}

\section{Participants and procedure}

Women faced with IPV in Gilan Gharb city, Kermanshah, Iran were studied. Inclusion criteria were experiencing IPV, the age range of 18-60 years, and having at least secondary education. Exclusion criteria were major depression (for minimizing the substantial effect of Major Depression Disorder [MDD] on dependant variables (Haagsma, Scholten, Andriessen, Vos, Van Beeck, \& Polinder, 2015), bipolar disorder, dysthymic disorder, or psychosis (according to self-report and the review of medical clinical reports), drug and alcohol abuse (drinking $>3$ times standard drinks a day or 12 times per week, consuming cannabis at least 2 times per week, and consuming other drugs regardless of the frequency or amount) (based on self-report and clinical medical records), being illiterate (no degree of at least secondary school), and failing to fulfill the study requirements. Given the extensive activity of the Committee on Relief to provide welfare services for traumatized people, the demographic information of them was available in this center and was used for screening potential participants.
We applied the purposive sampling method to recruit the subjects. Therefore, with the help of the authorities of the Committee, women with a history of being exposed to any type of IPV from October 2018 to March 2019 were contacted about the research by phone and we asked them to participate in this study if possible $(\mathrm{N}=374)$. If the subjects provided informed consent, the research team performed a primary symptom screening assessment. The subjects were asked to participate in a face-to-face interview. In the interview $(\mathrm{N}=239)$, they were evaluated regarding PTSD and Major Depression Disorder (MDD) by Structured Clinical Interview for DSM-5- Research Version (SCID-5-RV). Nineteen cases were excluded because of MDD. Each interview was audio-recorded and a second-rater evaluated 20\% of the transcripts for checking diagnostic criteria. There was full agreement between the evaluators. According to the interviews, 87 individuals met diagnostic criteria for PTSD and 133 individuals did not meet PTSD diagnostic criteria. We excluded 25 participants post-study because they did not respond to the scale completely (PTSD group $n=8$; non-PTSD group $n=17$ ). Thus, our final sample size was 195, including 79 individuals with PTSD (40.5\%) and 116 ones without PTSD (59.5\%), which was acceptable in terms of sample size according to the Morgan table. All subjects responded to the Affective and Emotional Composite Temperament Scale (AFECTS).

\section{Instruments}

Structured Clinical Interview for DSM-5- Research Version (SCID-5-RV): SCID-5 is a semi-structured interview guide that is used to make the major DSM-5 diagnoses. SCID-5-RV includes all of the relevant subtypes and intensity and course specifiers. Therefore, its dominant characteristic is its customizability, making it appropriate for meeting the requirements of certain research. The SCID-5-RV also has a standard "core" configuration, including the disorders that the majority of the investigators evaluate routinely in most studies, and an "enhanced" configuration containing many possible disorders, in addition to those from the "core" configuration (American Psychiatric Association, 2019).

Affective and Emotional Composite Temperament Scale (AFECTS): The AFECTS (Lara et al., 2012) has two sections, including the emotional section and the affective section.

The emotional section contains 48 items rated on a 7-point bipolar scale that assesses the emotional dimensions of coping, volition, inhibition, anger, sensitivity, and control (each with 8 items), and desire (4 items). The total 
score of each dimension can be determined by the sum of the scores of their related questions. With the exception of the desire dimension, every emotional dimension is made by two forms of four questions: volition (energy and positivity), anger (irritability and intensity), inhibition (caution and fear), sensitivity (interpersonal and to events), coping (solving and facing), and control (order and focus).

The affective section is rated on a 5-point Likert scale from 1 (nothing like me) to 5 (exactly like me), which has 12 affective temperaments, including anxious, depressive, apathetic, dysphoric, cyclothymic, obsessive, volatile euthymic, irritable, hyperthymic, euphoric, and disinhibited traits. This part is considered as the quantitative evaluation of affective temperament. After these
12 descriptions, the respondent is required to determine which profile represents his/her temperament in the best way. The classified evaluation of affective temperaments is described as follows:

Internalized types (including depressive, anxious, and apathetic mood states).

Unstable types (including dysphoric, cyclothymic, and volatile mood states)

Stable types (including euthymic, obsessive, and hyperthymic mood states)

Table 1. Demographic characteristics and symptom severity scores of the subjects

\begin{tabular}{|c|c|c|c|}
\hline \multirow{2}{*}{\multicolumn{2}{|c|}{ Variables }} & \multicolumn{2}{|c|}{ Mean $\pm S D /$ No. } \\
\hline & & PTSD $(n=79)$ & Non-PTSD $(n=116)$ \\
\hline Age (y) & & $30.38 \pm 8.56$ & $28.79 \pm 8.84$ \\
\hline Education & $\begin{array}{c}\text { Secondary education } \\
\text { Diploma } \\
\text { MA }\end{array}$ & $\begin{array}{c}22 \\
52 \\
5\end{array}$ & $\begin{array}{l}35 \\
67 \\
14\end{array}$ \\
\hline Family income (monthly) & $\begin{array}{c}x<100 \$ \\
100 \leq x<150 \$ \\
150 \$ \leq x\end{array}$ & $\begin{array}{l}46 \\
22 \\
11\end{array}$ & $\begin{array}{l}54 \\
38 \\
24\end{array}$ \\
\hline Marital status & $\begin{array}{l}\text { Single } \\
\text { Married }\end{array}$ & $\begin{array}{l}38 \\
41\end{array}$ & $\begin{array}{l}52 \\
64\end{array}$ \\
\hline
\end{tabular}

Table 2. Mean \pm SD scores of the affective temperament components by groups

\begin{tabular}{|c|c|c|}
\hline \multirow{2}{*}{ Affective Temperament Components } & \multicolumn{2}{|c|}{ Mean $\pm S D$} \\
\hline & PTSD & Non-PTSD \\
\hline Depressive & $3.18 \pm 1.33$ & $1.88 \pm 1.32$ \\
\hline Anxious & $3.15 \pm 1.26$ & $2.37 \pm 1.34$ \\
\hline Apathetic & $2.96 \pm 1.23$ & $1.85 \pm 1.01$ \\
\hline Cyclothymic & $3.35 \pm 1.21$ & $2.28 \pm 1.36$ \\
\hline Dysphoric & $3.11 \pm 1.13$ & $1.89 \pm 1.06$ \\
\hline Volatile & $3.15 \pm 1.24$ & $2.11 \pm 1.18$ \\
\hline Obsessive & $3.81 \pm 1.17$ & $2.68 \pm 1.33$ \\
\hline Euthymic & $3.24 \pm 1.26$ & $3.03 \pm 1.34$ \\
\hline Hyperthymic & $3.43 \pm 1.33$ & $3.1 \pm 1.51$ \\
\hline Irritable & $3.56 \pm 1.32$ & $2.56 \pm 1.21$ \\
\hline Disinhibited & $3.24 \pm 1.23$ & $2.04 \pm 1.1$ \\
\hline Euphoric & $3.49 \pm 1.15$ & $2.4 \pm 1.16$ \\
\hline
\end{tabular}


Table 3. Mean \pm SD scores of the emotional temperament components by groups

\begin{tabular}{|c|c|c|}
\hline \multirow{2}{*}{ Emotional Temperament Components } & \multicolumn{2}{|c|}{ Mean $\pm S D$} \\
\hline & PTSD & Non-PTSD \\
\hline Volition & $31.11 \pm 10.61$ & $32.83 \pm 12.12$ \\
\hline Anger & $32.81 \pm 8.02$ & $29.82 \pm 9.33$ \\
\hline Inhibition & $32.98 \pm 7.24$ & $30.78 \pm 8.68$ \\
\hline Sensitivity & $34.92 \pm 10.03$ & $28.75 \pm 8.61$ \\
\hline Coping & $33.58 \pm 9.91$ & $32.53 \pm 12.16$ \\
\hline Control & $33.41 \pm 10.81$ & $31.55 \pm 13.08$ \\
\hline
\end{tabular}

Externalized types (including disinhibited, irritable, and euphoric mood states) (Fuscaldo, Bisol, \& Lara, 2013).

Considering the affective and emotional temperament as the dependent variables and the group (PTSD vs. nonPTSD) as the independent variable of the study, the data were assessed by a one-way Multivariate Analysis of Variance (MANOVA) using SPSS v. 21 software.

\section{Results}

The participants' characteristics are provided in Table 1. There was no significant difference between the two groups in age $\left(\mathrm{F}_{(1,40)}=0.54, \mathrm{P}=0.23\right)$, level of education, $\left(\mathrm{x}^{2}{ }_{(2, \mathrm{~N}=195)}=3.26, \mathrm{P}=0.23\right)$, family income $\left(\mathrm{x}^{2}{ }_{(2, \mathrm{~N}=195)}=\right.$ $3.27, \mathrm{P}=0.14)$, or marital status $\left(\mathrm{x}^{2}{ }_{(2, \mathrm{~N}=195)}=2.82, \mathrm{P}=0.22\right)$.

PTSD and non-PTSD subjects differed significantly in terms of affective temperament, including depressive $\left(\mathrm{F}_{(1,50)}=28.84, \mathrm{P}<0.01, \eta_{\mathrm{p}}{ }^{2}=0.19\right)$, anxious $\left(\mathrm{F}_{(1,50)}=10.43\right.$, $\left.\mathrm{P}<0.01, \quad \eta_{\mathrm{p}}^{2}=0.08\right)$, apathetic $\quad\left(\mathrm{F}_{(1,50)}=29.06, \quad \mathrm{P}<0.01\right.$, $\left.\eta_{\mathrm{p}}{ }^{2}=0.20\right)$, cyclothymic $\left(\mathrm{F}_{(1,50)}=20.19, \mathrm{P}<0.01, \eta_{\mathrm{p}}{ }^{2}=0.14\right)$,

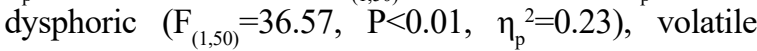
$\left(\mathrm{F}_{(1,50)}=22.11, \mathrm{P}<0.01, \eta_{\mathrm{p}}{ }^{2}=0.16\right)$, obsessive $\left(\mathrm{F}_{(1,50)}=23.19\right.$, $\left.\mathrm{P}<0.01, \quad \eta_{\mathrm{p}}^{2}=0.16\right), \quad$ irritable $\quad\left(\mathrm{F}_{(1,50)}=18.58, \quad \mathrm{P}<0.01\right.$, $\left.\eta_{\mathrm{p}}{ }^{2}=0.13\right)$, disinhibited $\left(\mathrm{F}_{(1,50)}=31.32, \mathrm{P}<0.01, \eta_{\mathrm{p}}{ }^{2}=0.21\right)$ and euphoric $\left(\mathrm{F}_{(1,50)}=29.92, \mathrm{P}<0.01, \eta_{\mathrm{p}}{ }^{2}=0.18\right)$ traits. Nevertheless, both groups did not differ significantly in terms of hyperthymic, $\left(\mathrm{F}_{(1,50)}=1.54, \mathrm{P}>0.05, \eta_{\mathrm{p}}{ }^{2}=0.013\right)$ and euthymic $\left(\mathrm{F}_{(1,50)}=4.68, \mathrm{P}>0.05, \eta_{\mathrm{p}}{ }^{2}=0.03\right)$ traits. Generally, except for hyperthymic and euthymic traits, other components of affective temperament were significantly higher in women suffering from PTSD than trauma-exposed women without PTSD (Table 2).

PTSD and non-PTSD subjects differed significantly in terms of emotional temperament, including an- ger $\left(\mathrm{F}_{(1,48)}=3.44, \mathrm{P}<0.05, \eta_{\mathrm{p}}^{2}=0.03\right)$, and sensitivity $\left(\mathrm{F}_{(1,48)}=13.16, \mathrm{P}<0.01, \eta_{\mathrm{p}}{ }^{2}=0.10\right)$; however, there were no significant differences between the two groups in terms of volition $\left(\mathrm{F}_{(1,48)}=0.67, \mathrm{P}>0.05, \eta_{\mathrm{p}}^{2}=0.006\right)$, inhibition $\left(\mathrm{F}_{(1,48)}=2.24, \mathrm{P}>0.05, \eta_{\mathrm{p}}^{2}=0.019\right)$, coping $\left(\mathrm{F}_{(1,48)}=0.26\right.$, $\left.\mathrm{P}>0.05, \eta_{\mathrm{p}}{ }^{2}=0.002\right)$, and control $\left(\mathrm{F}_{(1,48)}=0.69, \mathrm{P}>0.05\right.$, $\left.\eta_{\mathrm{p}}^{2}=0.006\right)$ (Table 3).

\section{Discussion}

This study was done to assess the affective and emotional temperaments in Iranian trauma-exposed women with and without PTSD following IPV. It is found that except for hyperthymic and euthymic traits, the mean scores of the group with PTSD were significantly higher than the trauma-exposed women without PTSD in the overall scores of affective temperaments, including anxious, depressive, apathetic, dysphoric, cyclothymic, volatile, disinhibited, obsessive, and euphoric traits. This finding is consistent with that of Marwaha et al. (2013) on the presence of greater unstable traits among PTSD patients. Moreover, our finding on the higher depressive trait in PTSD patients compared to non-PTSD individuals is in line with that of Roussos, Goenjian, and Steinberg (2005) and Roley, Claycomb, Contractor, Danger and Elhai (2015) who proposed a significant correlation between depression disorder and PTSD symptoms. Furthermore, our results are consistent with those of Weiss, Tull, Viana, Anestis, and Gratz (2012) on the association of impulsive behaviors with PTSD.

Our findings indicated that internalized, unstable, and externalized temperaments are correlated significantly with a greater risk of developing PTSD following trauma exposure. Internalized temperament is generally associated with anxiety and negative affectivity; individuals with internalized traits may react to stressful 
and traumatic events with passive avoidance that may act as a risk factor for developing PTSD. Unstable traits are characterized by the arousal of the autonomic nervous system, which may result in a rapid change in an emotional state. Furthermore, increased physiological arousal may keep the frightening trauma-related stimuli active in one's mind through intensifying the conditioning process. Lara et al. (2012) applied Eysenck's theory of extraversion in justifying externalized traits. Based on this theory, extraversion considers the individual differences in the rising reticular activating system, which is linked to the behavioral activation system; in this regard, elevated behavioral activation in externalized traits is also linked with high impulsivity (for review, see Lara et al., 2012). High impulsivity can be considered as a contributor to failure in emotion regulation in times of indicating negative mood; this may be seen in symptoms of hyper-arousal in PTSD patients. Accordingly, regarding the crucial link between impulsive behaviors and PTSD and the mediating role of emotional dysregulation on the relation of PTSD and impulsive behavior (Weiss et al., 2012), unstable traits and impulsive behaviors can be considered as the results of emotional dysregulation in PTSD patients. Powers, Cross, Fani, and Bradley. (2015) proposed the significant role of emotional dysregulation and PTSD symptoms in predicting dissociative symptoms in traumatized individuals. Shepherd and Wilde (2014) also suggested the contribution of PTSD symptoms to dysregulation issues, including negative emotions, higher controlled response, and lower application of cognitive changes.

Our results also showed significant differences between the two groups with and without PTSD in terms of emotional temperaments, including anger and sensitivity. Nevertheless, the two groups showed no significant difference in volition, inhibition, coping, and control, which is in line with the results of Jacob et al. (2007) on the presence of higher levels of anger in women with PTSD, and the findings of Berenz, Vujanovic, Coffey, and Zvolensky (2012), and Noohi et al. (2006) on the correlation between aggression and the severity of PTSD symptoms. Routinely, anger, which occurs as the result of failure to achieve one's desire or the happening of an unfavorable event acts as a strategy to lead the (activation) energy to defeat the barriers which stop gaining interest or dealing with events or disruptions, which results in the annoying events (Lara et al., 2012). Due to the high levels of anger representation in our subjects suffering from PTSD, our results confirm this point of view.

Sensitivity reflects the way that people react to common stressors, like interpersonal occurrences (rejection, criticism, offense) or general conditions (disappointment, trauma, pressure, and loss). Hence, the probability of developing conditioned fear is greater for individuals with higher sensitivity traits (Lara et al., 2012). Early life stressors may result in sensitivity raise and consequently, increase the risk of developing a mental disorder. Therefore, high sensitivity is a general risk factor for mental suffering and the development of mental disorders, like PTSD. Furthermore, sensitivity is possibly a major component of neuroticism in the Five-Factor Model as well as an important factor for harm avoidance according to Cloninger's model.

IPV can be one of the most detrimental experiences, which may result in psychiatric difficulties and socioeconomic burdens within each community (Weissman, 2007). IPV is no longer considered a private matter; it is regarded as a public health issue in every society (Dahlberg \& Mercy, 2009). In the Middle East countries, including Iran, IPV-affected women endure a noticeable lack of social and legal support due to the existing patriarchal culture and norms (Overstreet \& Quinn, 2013; Rowan, Mumford, \& Clark, 2015; Paul, 2016; Umubyeyi, Persson, Mogren, \& Krantz, 2016). There is no support for these women to access proper private or state organizations to seek legal help. Given the patriarchal nature of these countries, in which domestic violence and gender inequality are culturally accepted, these women are also deprived of informal help from their family, friends, or relatives. Hence, most of the IPVaffected women have no choice but to endure violence, and in some cases, live their lives under continuing threat and violence (Orang, 2018). Considering the effect of cultural factors on the processes underpinning PTSD (Jobson, 2009), more studies on trauma survivors from other cultural backgrounds are needed for the generalizability of the results.

\section{Conclusion}

This study for the first time investigated the affective and emotional temperaments in trauma-exposed Iranian women with and without PTSD following IPV via applying AFECTS. Nevertheless, some limitations should be taken into consideration. Applying self-report scales may limit the generalizability of our results. Considering the high rates of comorbidity between PTSD and MDD, excluding cases with comorbid MDD diagnosis may cause bias, possibly toward being less clinically severe. Also, although cases in the PTSD group had no other major psychiatric disorders, it was measured by self-report and review of their clinical medical records. This research could have been strengthened by considering a structured 
clinical diagnostic evaluation of these disorders. In addition, we assessed Iranian trauma survivors. Generally, regarding the current study results, applying the affective and emotional temperamental model in psychiatric clinical practice can be useful for many diagnostic issues, and may assist clinicians in diagnostic and treatment procedures.

\section{Ethical Considerations}

\section{Compliance with ethical guidelines}

All ethical principles are considered in this article. The participants were informed about the purpose of the research and its implementation stages. They were also assured about the confidentiality of their information. They were free to leave the study whenever they wished, and if desired, the research results would be available to them. We followed the 1964 Helsinki Declaration and its later amendments or comparable ethical standards.

\section{Funding}

This research didn't recieve any grants from funding agencies in the public, commercials, or non-profit sectors.

\section{Authors' contributions}

Conceptualization and supervision: Masumeh Shafiei and Sajjad Basharpoor; Methodology: Masumeh Shafiei and Somayeh Daneshvar; Investigation, writting - original draft, and writing - review and editing: All authors; Data collection: Masumeh Shafiei and Mina Taherifard; Data analysis: Somayeh Daneshvar.

\section{Conflict of interest}

The authors declared no conflict of interest.

\section{Acknowledgments}

We are thankful to the authorities of the Committee on Relief in Gilan-e-Gharb City and all participants.

\section{References}

Akiskal, H. S., Mendlowicz, M. V., Jean-Louis, G., Rapaport, M H., Kelsoe, J. R., \& Gillin, J. C., et al. (2005). TEMPS-A: Validation of a short version of a self-rated instrument designed to measure variations in temperament. Journal of Affective Disorders, 85(1-2), 45-52. [DOI:10.1016/j.jad.2003.10.012] [PMID]

Albanese, B. J., Norr, A. M., Capron, D. W., Zvolensky, M. J., \& Schmidt, N. B. (2015). Panic symptoms and elevated sui- cidal ideation and behaviors among trauma-exposed individuals: Moderating effects of post-traumatic stress disorder. Comprehensive Psychiatry, 61, 42-8. [DOI:10.1016/j. comppsych.2015.05.006] [PMID] [PMCID]

American Psychiatric Association Publishing. (2019). The structured clinical interview for DSM-5®. Retrieved from https:// www.appi.org/products/structured-clinical-interview-fordsm-5-scid-5

Berenz, E. C., Vujanovic, A. A., Coffey, S. F., \& Zvolensky, M. J. (2012). Anxiety sensitivity and breath-holding duration in relation to PTSD symptom severity among trauma-exposed adults. Journal of Anxiety Disorders, 26(1),134-9. [DOI:10.1016/j. janxdis.2011.10.004] [PMID] [PMCID]

Brown, W. J., Bruce, S. E., Buchholz, K. R., Artime, T. M., $\mathrm{Hu}, \mathrm{E} .$, \& Sheline, Y. I. (2014). Affective dispositions and PTSD symptom clusters in female interpersonal trauma survivors. Journal of Interpersonal Violence, 31(3), 407-24. [DOI:10.1177/0886260514555866] [PMID]

Carta, M. G., Balestrieri, M., Murru, A., \& Hardoy, M. C. (2009). Adjustment disorder: Epidemiology, diagnosis, and treatment. Clinical Practice and Epidemiology in Mental Health, 5, 15 [DOI:10.1186/1745-0179-5-15] [PMID] [PMCID]

Chossegros, L., Hours, M., Charnay, P., Bernard, M., Fort, E., \& Boisson, D., et al. (2011). Predictive factors of chronic posttraumatic stress disorder 6 months after a road traffic accident Accident Analysis and Prevention, 43(1), 471-7. [DOI:10.1016/j. aap.2010.10.004] [PMID]

Clapp, J. D., Patton, S. C., \& Beck, J. G. (2015). Expressive inhibition in response to stress: Implications for emotional processing following trauma. Journal of Anxiety Disorders, 29, 109-18. [DOI:10.1016/j.janxdis.2014.11.008] [PMID] [PMCID]

Clark, L. A. (2005). Temperament as a unifying basis for personality and psychopathology. Journal of Abnormal Psychology, 114(4), 505-21. [DOI:10.1037/0021-843X.114.4.505] [PMID]

Cloninger, C. R., Svrakic, D. M., \& Przybeck, T. R. (1993). A psychobiological model of temperament and character. Archives of General Psychiatry, 50(12), 975-90. [DOI:10.1001/ archpsyc.1993.01820240059008] [PMID]

Cyniak-Cieciura, M., \& Zawadzki, B. (2019). The relationship between temperament traits and post-traumatic stress disorder symptoms and its moderators: Meta-analysis and meta-regression. Trauma, Violence $\mathcal{E}$ Abuse, 22(4), 702-16. [DOI:10.1177/1524838019876702] [PMID]

Dahlberg, L. L., \& Mercy, J. A. (2009). History of violence as a public health problem. Virtual Mentor, 11(2), 167-72. [DOI:10.1001/virtualmentor.2009.11.2.mhst1-0902] [PMID]

Duffy, R. D., Jadidian, A., Douglass, R. P. \& Allan, B. A. (2015). Work Volition among U.S. veterans locus of control as a mediator. Counseling Psychologist, 43(6), 853-78. [DOI:10.1177/0011000015576800]

Forbes, D., Elhai, J. D., Miller, M. W., \& Creamer, M. (2010). Internalizing and externalizing classes in posttraumatic stress disorder: A latent class analysis. Journal of Traumatic Stress, 23(3), 340-9. [DOI:10.1002/jts.20526] [PMID]

Fuscaldo, L. V., Bisol, L. W., \& Lara, D. R. (2013). How emotional traits and affective temperaments relate to cocaine experimentation, abuse, and dependence in a large sample. 
Journal of Addictive Behaviors, 38(3), 1859-64. [DOI:10.1016/j. addbeh.2012.11.009] [PMID]

Golding, J. M. (1999). Intimate partner violence as a risk factor for mental disorders: A meta-analysis. Journal of Family Violence, 14(2), 99-132. [DOI:10.1023/A:1022079418229]

Gray, J. A. (1991). Neural systems, emotion and personality. In J. Madden IV (Ed.), Neurobiology of Learning, Emotion and Affect. New York: Raven Press. https://www.google.com/books/ edition/Neurobiology_of_Learning_Emotion_and_Aff/ pPtqAAAAMAAJ?hl=en

Haagsma, J. A., Scholten, A. C., Andriessen, T. M. J. C., Vos, P. E., Van Beeck, E. F., \& Polinder, S. (2015). Impact of depression and post-traumatic stress disorder on functional outcome and health-related quality of life of patients with mild traumatic brain injury. Journal of Neurotrauma, 32(11), 853-62. [DOI:10.1089/neu.2013.3283] [PMID]

Jacob, G. A., Guenzler, C., Zimmermann, S., Scheel, C. N., Rüsch, N., \& Leonhart, R., et al. (2007). Time course of anger and other emotions in women with borderline personality disorder: A preliminary study. Journal of Behavior Therapy and Experimental Psychiatry, 39(3), 391-402. [DOI:10.1016/j. jbtep.2007.10.009]

Jan, S., \& Bogdan, Z. (2004). Trauma and temperament as predictors of posttraumatic stress disorder and its dimensions 3,15 months and two years after experiencing a flood. Polish Psychological Bulletin, 10(2), 124-35. [DOI:10.1027/10169040.10.2.124]

Jobson, L. (2009). Drawing current posttraumatic stress disorder models into the cultural sphere: The development of the "threat to the conceptual self" model. Clinical Psychology Review, 29(4), 368-81. [DOI:10.1016/j.cpr.2009.03.002] [PMID]

Karvat Gracia, D. F., Lara, D. R., Ottoni, G. 1., \& de Araújoc, R. M. F. (2019). Analysis of association between temperament and psychological symptoms using the Affective and Emotional Composite Temperament (AFECT) model: An internet-based survey. Journal of Affective Disorders, 264, 446-54. [DOI:10.1016/j.jad.2019.11.073] [PMID]

Kotov, R., Gamez, W., Schmidt, F., \& Watson, D. (2010). Linking "big" personality traits to anxiety, depressive, and substance use disorders: A meta-analysis. Psychological Bulletin, 136(5), 768-821. [DOI:10.1037/a0020327] [PMID]

Lara, D. R., Bisol, L. W., Brunstein, M. G., Reppold, C. T., de Carvalho, H. W., \& Ottoni, G. L. (2012). The Affective and Emotional Composite Temperament (AFECT) model and scale: A system-based integrative approach. Journal of Affective Disorders, 140(1), 14-37. [DOI:10.1016/j.jad.2011.08.036] [PMID]

Marwaha, S., Parsons, N., \& Broome, M. (2013). Mood instability, mental illness, and suicidal ideas: Results from a household survey. Social Psychiatry and Psychiatric Epidemiology, 48(9), 1431-7. [DOI:10.1007/s00127-013-0653-7] [PMID]

Miller, M. W. (2003). Personality and the etiology and expression of PTSD: A three factor model perspective. Clinical Psychology: Science and Practice, 10(4), 373-93. [DOI:10.1093/ clipsy.bpg040]

Miller, M. W., \& Resick, P. A. (2007). Internalizing and externalizing subtypes in female sexual assault survivors: Implications for the understanding of complex PTSD. Behavior Therapy, 38(1), 58-71. [DOI:10.1016/j.beth.2006.04.003] [PMID] [PMCID]
Miller, M. W., Greif, J. L., \& Smith, A. A. (2003). Multidimensional Personality Questionnaire profiles of veterans with traumatic combat exposure: Externalizing and internalizing subtypes. Psychological Assessment, 15(2), 205-15. [DOI:10.1037/10403590.15.2.205] [PMID]

Moghaddam Hosseini, V., Asadi, Z. S., Akaberi, A., \& Hashemian, M. (2013). Intimate partner violence in the eastern part of Iran: A path analysis of risk factors. Issues in Mental Health Nursing 34(8), 619-25. [DOI:10.3109/01612840.2013.785616] [PMID]

Noohi, S., Azar, M., Shafiei Kandjani, A., Tavallaee, S. A., Karami, G., \& Raadfar, S., et al. (2006). [Studying the relation of aggression with the clinical severity of post-traumatic stress disorder (Persian)]. Researcher Bulletin of Medical Science, 11(50), 95-9. https://www.sid.ir/fa/journal/ViewPaper. aspx?id=53573

Orang, T. (2018). Continuous intimate partner violence. Mental health consequences and feasibility of psychological interventions: The case of Iran [PhD dissertation]. Konstanz: University of Knostanz. http://kops.uni-konstanz.de/bitstream/ handle/123456789/43122/Orang_2-18yglnubmjzie4.

Overstreet, N. M., \& Quinn, D. M. (2013). The intimate partner violence stigmatization model and barriers to help seeking. Basic and Applied Social Psychology, 35(1), 109-22. [DOI:10.1080 /01973533.2012.746599] [PMID] [PMCID]

Patrick, C. J., \& Bernat, E. M. (2006). The construct of emotion as a bridge between personality and psychopathology. In R. F. Krueger, \& J. Tackett (Eds.), Personality and Psychopathology (pp. 174-209). New York: Guildford Press. https://www.google.com/books/edition/Personality_and_ Psychopathol=frontcover

Paul, S. (2016). Intimate partner violence and women's helpseeking behaviour: Evidence from India. Journal of Interdisciplinary Economics, 28(1), 53-82. [DOI:10.1177/0260107915609818]

Powers, A., Cross, D., Fani, N., \& Bradley, B. (2015). PTSD, emotion dysregulation and dissociative symptoms in a highly traumatized sample. Journal of Psychiatric Research, 61, 1749. [DOI:10.1016/j.jpsychires.2014.12.011] [PMID] [PMCID]

Roley, M. E., Claycomb, M. A., Contractor, A. A., Danger, P., \& Elhai, C. J. (2015). The relationship between rumination, PTSD, and depression symptoms. Journal of Affective Disorders, 180, 116-21. [DOI:10.1016/j.jad.2015.04.006] [PMID]

Roussos, A., Goenjian, A., \& Steinberg, A. (2005). Posttraumatic stress and depressive reactions among children and adolescents after the 1999 earthquake in Ano Liosina, Greece. American Journal of Psychiatry, 162(3), 530-7. [DOI:10.1176/appi. ajp.162.3.530] [PMID]

Rowan, K., Mumford, E., \& Clark, C. J. (2015). Is women's empowerment associated with help-seeking for spousal violence in India? Journal of Interpersonal Violence, 33(9), 1519-48. [DOI:10.1177/0886260515618945] [PMID] [PMCID]

Rzeszutek, M., Oniszczenko, W., Schier, K., Biernat-Kałuża, E., \& Gasik, R. (2015). Trauma symptoms, temperament traits, social support and the intensity of pain in a Polish sample of patients suffering from chronic pain. Personality and Individual Differences, 83, 13-7. [DOI:10.1016/j.paid.2015.03.036]

Shepherd, L., \& Wild, J. (2014). Emotion regulation, physiological arousal and PTSD symptoms in trauma-exposed individuals. Journal of Behavior Therapy and Experimental Psychiatry, 45(3), 360-7. [DOI:10.1016/j.jbtep.2014.03.002] [PMID] [PMCID] 
Umubyeyi, A., Persson, M., Mogren, I., \& Krantz, G. (2016). Gender inequality prevents abused women from seeking care despite protection given in gender-based violence legislation: A qualitative study from Rwanda. PLoS ONE, 11(5), 1-13. [DOI:10.1371/journal.pone.0154540] [PMID] [PMCID]

Vameghi, M., Khodaie Ardakani, M., \& Sajjadi, H. (2013). [Domestic violence in Iran: Review of 2001-2008 literature (Persian)]. Social Welfare Quarterly, 13(50), 37-70. http://refahj. uswr.ac.ir/article-1-1354-en.html

Walker, L. E. (1999). Psychology and domestic violence around the world. American Psychologist, 54(1), 21-9. [DOI:10.1037/0003-066X.54.1.21]

Weiss, N. H., Tull, M. T., Viana, A. G., Anestis, M. D., \& Gratz, K. L. (2012). Impulsive behaviors as an emotion regulation strategy: Examining associations between PTSD, emotion dysregulation, and impulsive behaviors among substancedependent inpatients. Journal of Anxiety Disorders, 26(3), 453-8. [DOI:10.1016/j.janxdis.2012.01.007] [PMID] [PMCID]

Weissman, D. M. (2007). The personal is political-and economic: Rethinking domestic violence. BYU Law Review, 387. https:// heinonline.org/HOL/LandingPage?handle=hein.jour

Widiger, T. A., \& Smith, G. T. (2008). Personality and psychopathology. In O. P. John, R. W. Robins, \& L. A. Pervin (Eds.), Handbook of Personality: Theory and Research (pp. 743-69). New York: Guilford Press. https://www.google.com/books/edition/Handbook_of_Personality/olgW-du4RBcC?r

Wineman, N. M., Woods, S. J., \& Zupanic, M. K. (2004). Intimate Partner Violence as a Predictor of Post-Traumatic Stress Disorder Symptom Severity in Women. Paper presented at the Sigma Theta Tau's 15th International Research Congress: Building Community Through Research, Dublin, Ireland, 2224 July 2004. https:/ / scholar.google.com/scholar?hl=en\&as $\mathrm{sdt}=0 \% 2 \mathrm{C} 5 \& \mathrm{q}=$ Intimate + partner+violence $+\mathrm{as}+\mathrm{a}+$ predictor +

World Health Organization (WHO). (2017). Violence against women: Global picture health response. Retrieved from http://www.who.int/reproductivehealth/publications/violence/VAW_infographic.pdf

Zawadzki, B., \& Agnieszka, P. (2012). Temperamental traits and severity of PTSD symptoms: Data from longitudinal studies of motor vehicle accident survivors. Journal of Individual Differences, 33(4), 257-67. [DOI:10.1027/1614-0001/a000074] 